\title{
Computational Analysis of Specific Indicators to Manage Crop Yield and Profits Under Extreme Heat and Climate Change Conditions
}

\section{Maya Sharma}

Project Mentor: Dr. Caleb Pan

Project Sponsor: Steve Mantle 


\section{Abstract}

The US pacific northwest recorded its highest temperature in late June 2021. The three-day stretch of scorching heat had a devastating effect on not only the residents of the state, but also on the crops thus impacting the food supply-chain. It is forecasted that streaks of 100-degree temperatures will become common. Farmers will have to adapt to the changing landscape to preserve their crop yield and profitability. A research collaborative consisting of researchers and academicians in Eastern Washington led by a pioneering startup has setup a 16.9-acre Honeycrisp Apple Smart Orchard in Grandview, WA as a laboratory to study the environmental and plant growth factors in real-time using modern computational tools and techniques like IoT (Internet of Things), Edge and Cloud Computing, and Drone and LiDAR (Light Detection and Ranging) imaging. The computational analysis is used to develop guidelines for precision agriculture for orchard blocks to address plant growth issues scientifically and in a timely fashion. The analysis also helps in creating risk-mitigation strategies for severe weather events while helping prepare farmers to maximize crop yield and profitability per acre. I was fortunate to gain access to the terabytes of farm data related to the weather, soil, water, tree, and canopy health, to analyze and formulate recommendations for the farmers that can be adopted nationwide for different crops and weather conditions. This paper discusses the different streams of farm data that were analyzed (ex. soil moisture, soil water potential, and sap flow) and the development of the framework to use data to convert insights into actionable steps. For example, the use of sensors can inform a farmer that their level of soil water potential is below threshold in a specific patch of the orchard, prompting them to turn on irrigation for the patch instead of the whole orchard. I estimate that using an IoTsensor-based decision framework discussed in this paper, growers can save up to $55 \%$ of their water costs for the season. Using these insights, farmers can better manage their irrigation resources and labor, thus maximizing their crop yield and profits.

\section{Keywords}

Agriculture; Extreme Heat; Climate Change; Grandview; Edge Computing; 5G; IoT; Drone Imagery; LiDAR; Decision framework 


\section{Background and Purpose}

The Intergovernmental Panel on Climate Change (IPCC), the United Nations body tasked with assessing the climate change risks has been researching and documenting in great detail how our planet is heating up faster than ever. ${ }^{1}$ In their latest report, the group stated that, "the Global temperature will continue to increase until at least the mid-century under emissions scenarios considered" and expect global warming of $1.5^{\circ} \mathrm{C}$ and $2^{\circ} \mathrm{C}$ during this century unless gas emissions are severely reduced. ${ }^{2}$ According to the National Oceanic and Atmospheric Administration's (NOAA) Global Climate Report for 2020, 2011-2020 was the warmest decade on record for the globe, with a surface global temperature of $+1.48^{\circ} \mathrm{F} .{ }^{3}$ Furthermore, the number of extreme weather events are increasing in frequency and the ferocity of these events is breaking all sorts of regional and national records. One such event occurred in the Pacific Northwest in late June 2021. In what was described as the heat dome, the temperatures soared above $100^{\circ} \mathrm{F}$ for three straight days (highly unusual for the region) which engulfed the region in unrelenting heat. Several hundreds of people died. ${ }^{4}$ Further, the heatwave had a devastating impact on the food supply-chain as the drought conditions, low soil-moisture, and incessant heat baked crops such as cherries and potatoes, rendering them to waste. Other perennials like apples were also impacted as severe heat exposure stresses the plant, arrests fruit development, and accelerates plant mortality. Such conditions also tax the water supply necessary for irrigation and increase the operational and labor costs for operating under extreme conditions.

\section{Competition for water}

Projected water stress around the world by riskzone, 2030

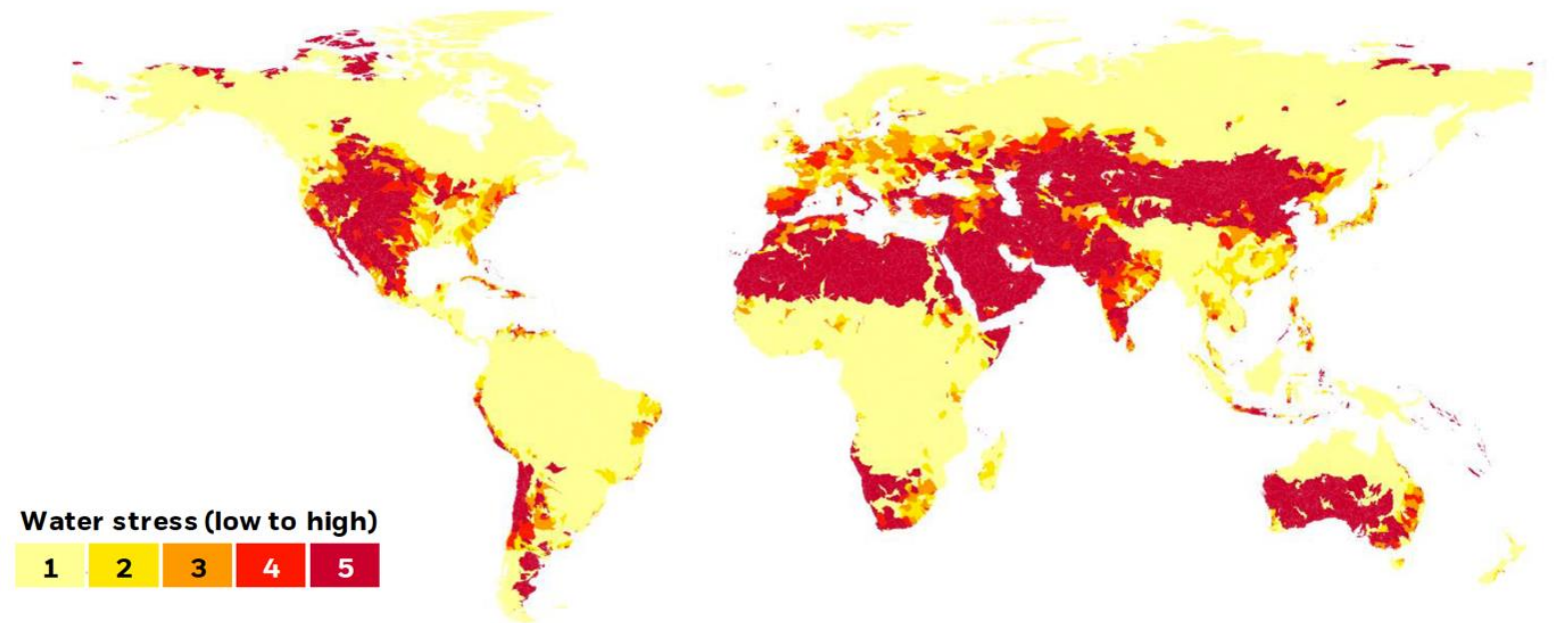

Figure 1. Water stress 5 
The heat related stress phenomenon is universal and is impacting other states in the US and countries around the world. In its paper, the United States Department of Agriculture (USDA) highlighted how extreme heat will challenge agricultural production and raise the risk of food insecurity ${ }^{6,7}$. Thus, the combination of lower yield and higher costs impact the profitability for farmers negatively. It is unlikely that we can reverse the climate change trajectory in the short-term therefore, we must develop risk mitigation strategies to minimize the damage, preserve the crop yield, and maximize profits for the sustainability of the food supply-chain.

Water stress has been gradually increasing around the world (Figure 1). The supply of water through natural processes is roughly the same. However, the global demand for water has been increasing at a pace of $1 \%$ annually in the past decades due to the growing urban population. ${ }^{8}$ The risk is especially severe on sectors such as agriculture, power, and food supply. The risk has increased so much that large investment hedge funds are starting to assess their investments in these categories based on the water risk by industrial sector and geography.

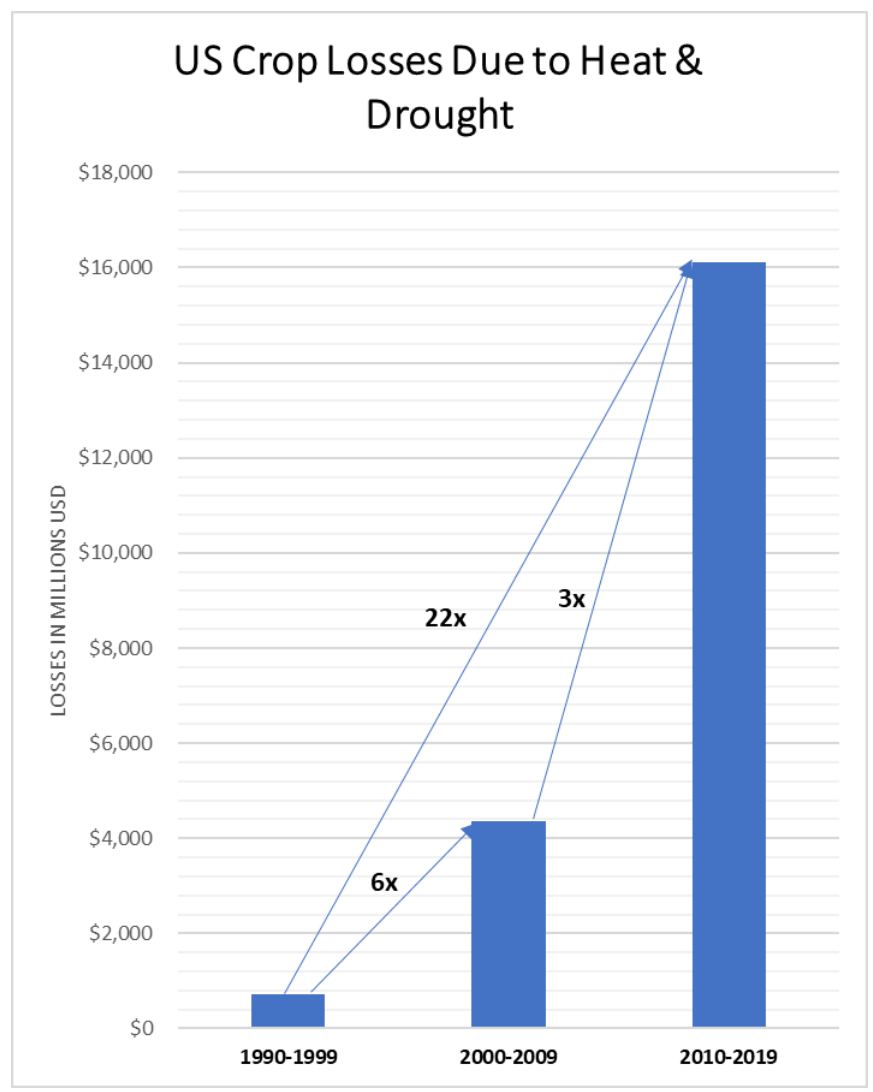

Figure 2. US crop losses due to heat and drought over the last three decades 9 
By studying the insurance data collected by the USDA over the last three decades (Figure 2), it is clear that the crop losses due to heat and drought are multiplying each decade. The crop losses due to heat and drought during 2010-2019 in the US were over \$16 billion which was 22 times more than the losses during 1990-1999 and 3 times more compared to the preceding decade of 20002009. Based on the way which heatwaves are occurring across the country, it is highly likely that the decade of 2020-2029 will see severe heat related crop losses in the US. While policy makers are working on addressing the climate change threat, farmers need immediate relief that helps in the short-term and prepares them better for the long-term.

Agriculture accounts for $85 \%$ of human water consumption, yet we do not manage it like a valuable resource. ${ }^{10}$ Once we assign value to the water used for irrigation based on crop and region, we can start to appreciate it more as well as develop strategies to use it efficiently. We need technologies and policies to manage our water supply better. Such an approach will help farmers and governments develop strategies based the value of water by crop and region.

New technologies such as IoT, Edge Computing, Wireless Mesh Networking, Drone Imaging, LiDAR imaging, and others have been used sporadically by farmers to gain insights into what's happening on the ground. However, the data feeds are generally not used together to formulate a holistic strategy for the specific farm. Often times, the data from various sensors on the farm reside in different databases and cloud or local repository without the ability to combine the datasets for deeper insights. For the 2021 growing season, an innovative AgTech startup, innov8.ag, was commissioned to sensorize a Smart Orchard in Grandview, WA to focus on honey crisp apples - a high value and water sensitive variety. ${ }^{11}$ Apple is an important crop for WA economy. WA apples account for $65 \%$ of all US fresh apple production and for $95 \%$ of all US apple exports. ${ }^{12}$ This Smart Orchard is a commercial orchard operated by Washington Fruit, one of the largest apple producers in the US. ${ }^{13}$ This is a research partnership between researchers from Washington State University (WSU), Washington Tree Fruit Research Commission, and innov8.ag. Industry collaborators include FloraPulse, Dynamax, Thingy, Aker Ag, CropVue, Ceres, SoilOptix, GreenAtlas, and Arable.

Collectively, the researchers from these organizations have setup IoT sensors to harness the near real-time data from the orchard and feed it into a centralized cloud repository. This dataset, when reviewed with imagery data from drones and LiDAR, provides a complete view of the growth patterns and environmental data at a highly granular level that can be studied over the course of the growing season. I was able to work with innov8.ag and other researchers at WSU to gain access to the data from these sensors as well as the imaging data to analyze the patterns over the four- 
month time period for this project. The goal of the project was to examine if we could use the critical threshold levels to monitor the orchard for growth and vitality and develop irrigation strategies that maximize yield and profitability per acre. Dr. Caleb Pan at innov8.ag was my mentor and guide for this project and Steve Mantle, CEO and Founder of innov8.ag was the sponsor as he provided guidance and support throughout the project. In the next section, I will discuss the various data sources and method of collection for analysis.

\section{Methods and Data collection}

The Grandview orchard had several sensors placed throughout the field (as illustrated in Figure 3). Further, drones and ATV were used for additional data collection. The basic set of data collected from various sensors can be categorized by the frequency the data is being collected. The drone imagery data, using multispectral and thermal infrared cameras, is collected monthly to get a bird's eye view of the canopy for mapping Normalized Difference Vegetation Index (NDVI), canopy/soil temperature, soil water potential, and evapotranspiration (water use).

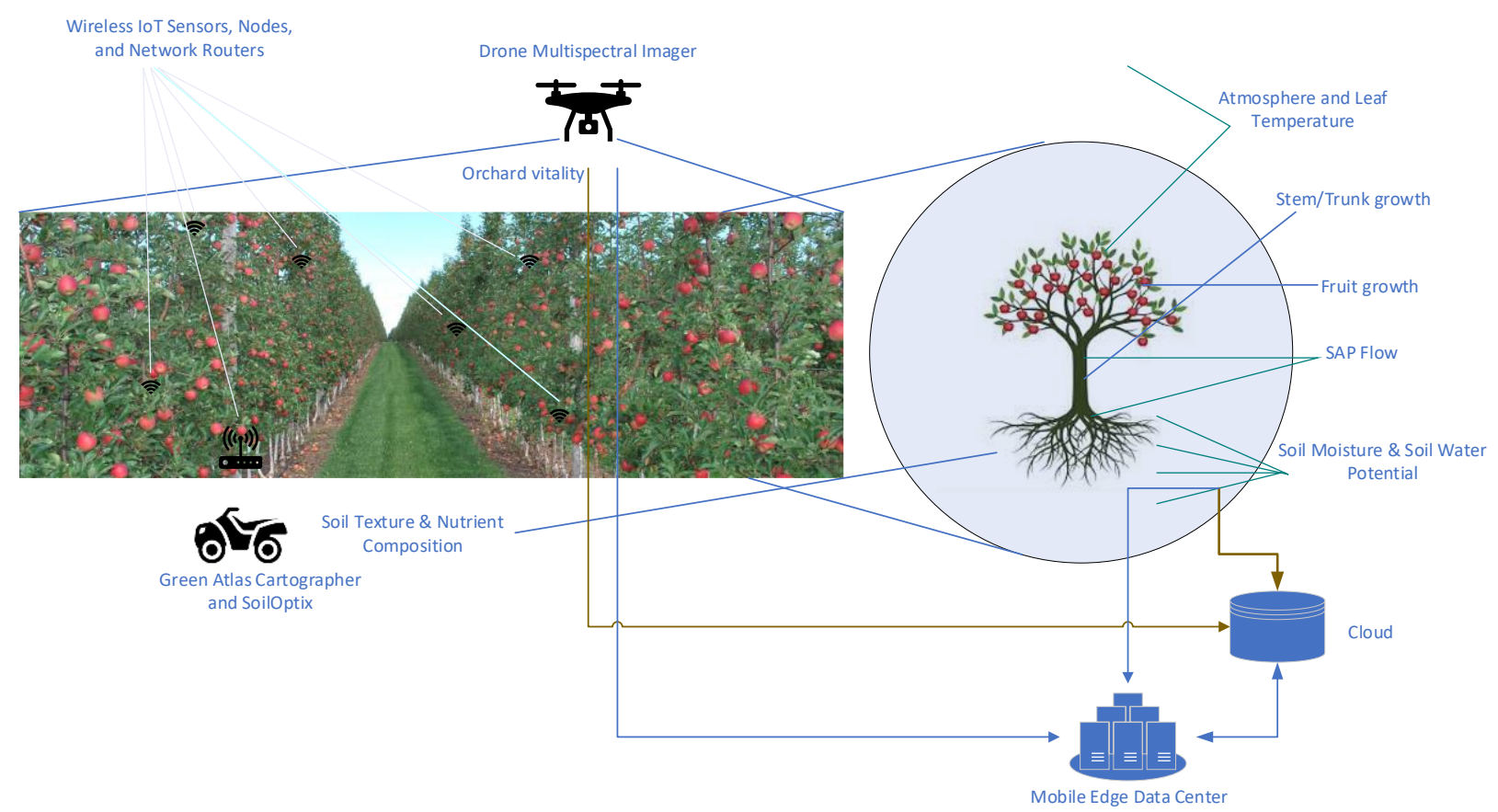

Figure 3. Sensor placement in Grandview apple orchard

innov8.ag's high-resolution ATV-based imagery is used to quantify the growth and number of the crop across the orchard. It is used to track progress of the fruit from its flower stage to applet stage to apple stage for yield prediction as well as the health of the orchard at the single tree level. The ATV is also fitted with Green Atlas Cartographer and SoilOptix Digital Top Soil Mapping sensors to 
gain insights into the status of soil nutrients and texture variability that are essential for plant growth. ATV data can be collected every 1-2 weeks.

The IoT family of sensors across the orchard collect data on a more frequent basis (Table 1). The timing varies from 5-15-minute intervals depending on the sensor and what specific variable it is measuring. The table above provides a summary of the various sensors and what they are measuring.

Table 1. Sensor details

\begin{tabular}{|c|c|c|c|c|}
\hline Sensor & Provider & Measurement & Frequency & Insights \\
\hline $\begin{array}{l}\text { Drone } \\
\text { multispectral } \\
\text { imager }\end{array}$ & WSU & $\begin{array}{l}\text { Spatial Resolution: } \\
7 \mathrm{~cm} @ 100 \mathrm{~m} \\
\text { altitude Accuracy: } \\
\text { > 90\%; Green-1: } \\
532 \mathrm{~nm} \text {, Green-2: } \\
570 \mathrm{~nm} \text {, Red: } 650 \\
\text { nm; NIR: } 810 \mathrm{~nm} \text {, } \\
\text { thermal and RGB } \\
\text { (NDVI) }\end{array}$ & Monthly & $\begin{array}{l}\text { Orchard vitality and } \\
\text { greenness of the orchard. } \\
\text { Detection of stressed } \\
\text { segments }\end{array}$ \\
\hline $\begin{array}{l}\text { Green Atlas } \\
\text { Cartographer }\end{array}$ & Innov8.ag & $\begin{array}{l}\text { Fruit/bloom count, } \\
\text { fruit size, height, } \\
\text { area, density, fruit } \\
\text { color }\end{array}$ & 1-2 weeks & $\begin{array}{l}\text { Crop yield and vitality. } \\
\text { Benchmarking }\end{array}$ \\
\hline SoilOptix & innov8.ag & $\begin{array}{l}\text { Nutrient } \\
\text { composition, NPK, , } \\
\text { salinity, } 30+\text { macro } \\
\& \text { micro nutrients, } \\
\text { soil texture, pH, } \\
\text { and organic matter } \\
\text { in } 10 \text { 'x10' grid }\end{array}$ & 1-2 weeks & $\begin{array}{l}\text { Soil nutrient composition } \\
\text { and detection of stress }\end{array}$ \\
\hline $\begin{array}{l}\text { Leaf \& Canopy } \\
\text { Temperature }\end{array}$ & Dynamax & Temperature $\left({ }^{\circ} \mathrm{F}\right)$ & $10-15$ mins & $\begin{array}{l}\text { Temperature growth in } \\
\text { the region as well as } \\
\text { specific orchard zones. } \\
\text { Irrigation trigger zones }\end{array}$ \\
\hline Sap Flow & Dynamax & Sap flow (gal/hr) & $15-30$ mins & $\begin{array}{l}\text { Plant vigor and detection } \\
\text { of heat stress }\end{array}$ \\
\hline $\begin{array}{l}\text { Fruit and Stem } \\
\text { growth }\end{array}$ & Dynamax & Shrink-swell in $\mu \mathrm{m}$ & Hourly & $\begin{array}{l}\text { Growth patterns and } \\
\text { benchmarking }\end{array}$ \\
\hline Soil Moisture & Dynamax & R: $0.1 \mathrm{kPa}, \mathrm{A}: 90 \%$ & $10-15$ mins & Detection of heat stress \\
\hline $\begin{array}{l}\text { Soil Water } \\
\text { Potential }\end{array}$ & Edaphic Scientific & $\begin{array}{l}\text { Soil Water } \\
\text { Potential in } \mathrm{kPa}\end{array}$ & 10-15 mins & $\begin{array}{l}\text { State of soil stress or } \\
\text { saturation }\end{array}$ \\
\hline
\end{tabular}

The real power of this setup is that once the data is in the cloud and is normalized, the aggregated data can be visualized, analyzed, interpreted, and compared to other datasets from other farms or historical data with significant ease. It can lead to new insights that just aren't possible without the centralized cloud. 


\section{Data Analysis and Results}

In this section, I will discuss the data analysis from the various sensors and their importance in developing a framework that can be used by the farmers for managing irrigation resources.

\section{Drone Imagery Data}

Figure 4 shows the drone imagery that depicts NDVI for the orchard. We can assess the NDVI value (NDVI values are on the scale of 0 to 1 , the higher value indicates higher level of greenness in the segment; as the trees get denser during the summer due to growing leaves, the NDVI value rises) for each such segment, compare it to other segments in the orchard, and measure progress over time. The darker the segment, the greener it is, indicating vitality and high vigor for the orchard. As the growing season progresses, the orchard gets greener but as one can see, around the top right edges of the orchard, these segments are less green. Similarly, there are patches in between rows that are not as green as most others in the orchard. Figure 5 shows the 16.9 -acre field divided into 1,507 sections, where each segment is 30 feet long. This allows for computational analysis of the orchard at a very granular level.

April 2021

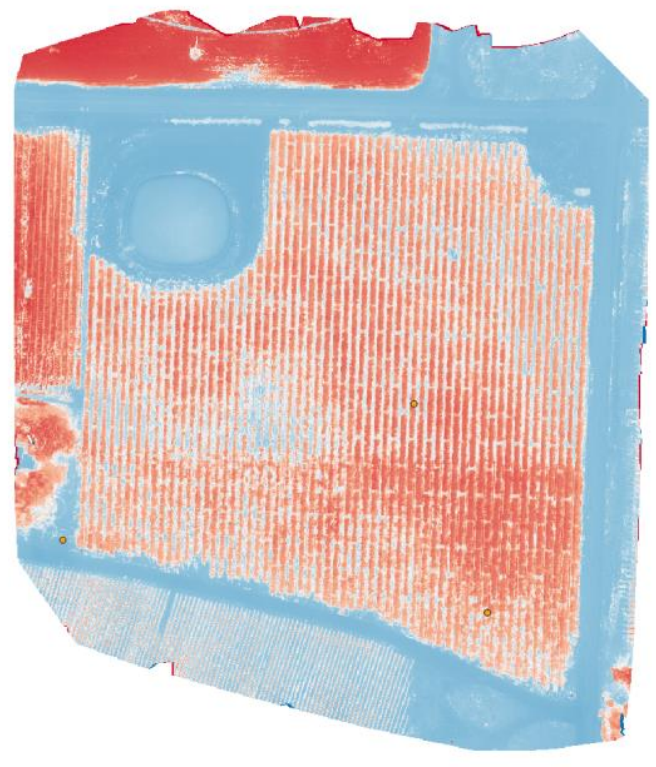

June 2021

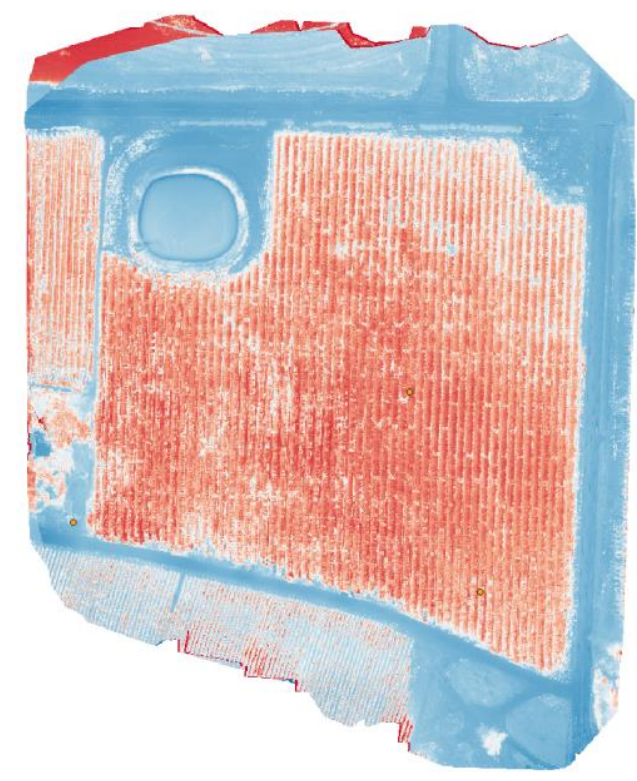

Figure 4. Drone imagery of the Grandview orchard in April and June 2021 (The darker the color, the greener is the orchard segment)

The circles shown in Figure 5a-b are the sensor locations that measure the temperature, soil moisture, sap flow, and other environmental and plant growth variables. The drone imagery can 
direct the farmers about the placement of such sensors within the orchard both for comparative analysis and benchmarking.

NDVI is calculated from the drone imagery data. The NDVI data is then compared across three months of April (spring), June (heat wave), and July (peak growth). Figure 6. shows average NDVI across all the segments in the orchard for different sensor locations. Figure 7. shows the histogram of all segment values across the orchard for three different months. As expected, the histogram is moving towards the right, indicating that the orchard is getting greener with time. However, the real power of the drone imagery comes not only from the overview of the orchard and insights into its progression during the growing season, but also from finding specific segments in the orchard that require more attention.

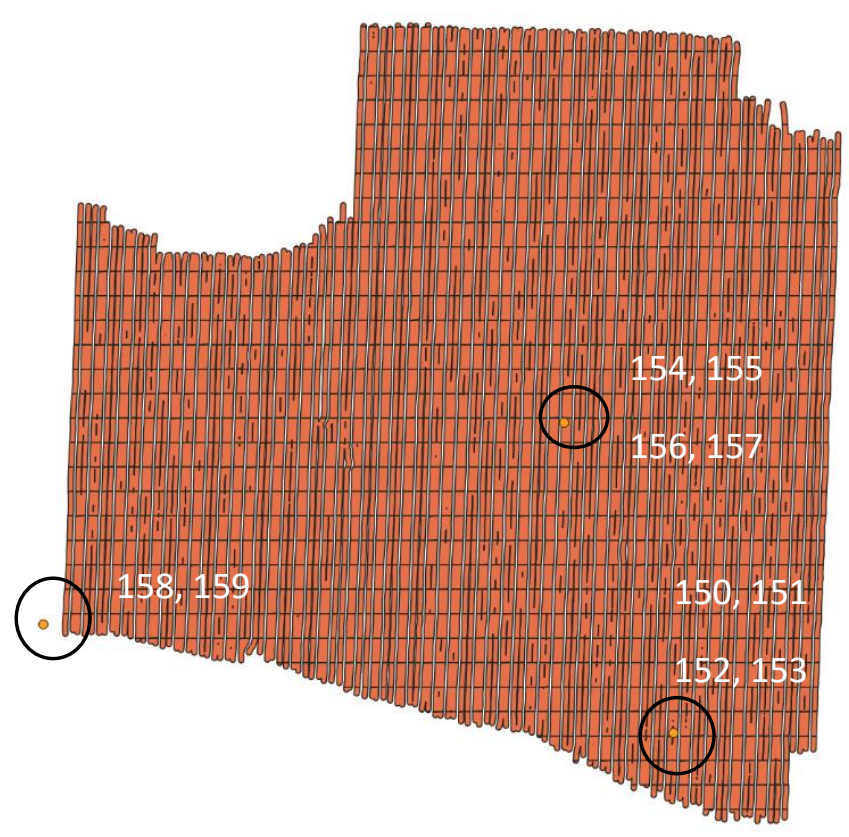

(a)

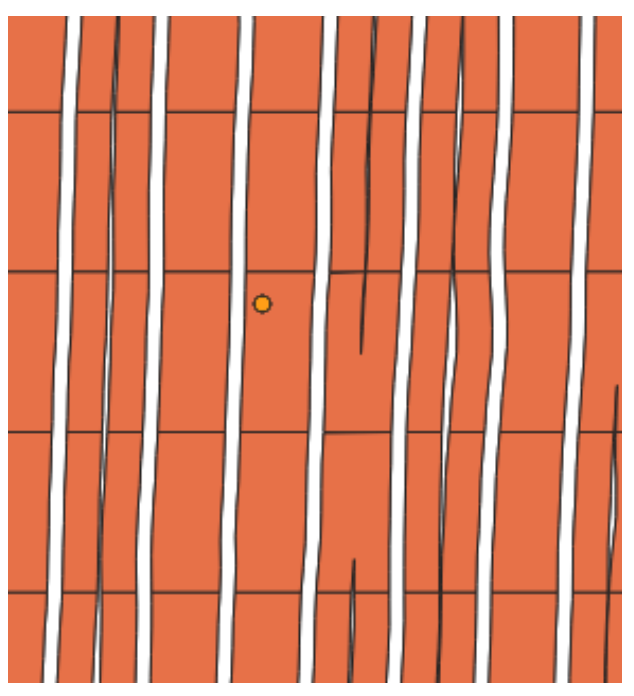

(b)

Figure 5. a) The Grandview orchard split by 30 feet segment. The circles indicate the location of the sensors in the orchard. b) This image is a zoomed version showing the location of the sensor set. Each location id (represented by numbers 150-159) refers to a specific set of sensors that measure weather and soil parameters like air temperature, atmospheric and vapor pressure, leaf wetness, precipitation, soil water potential, wind, etc. 


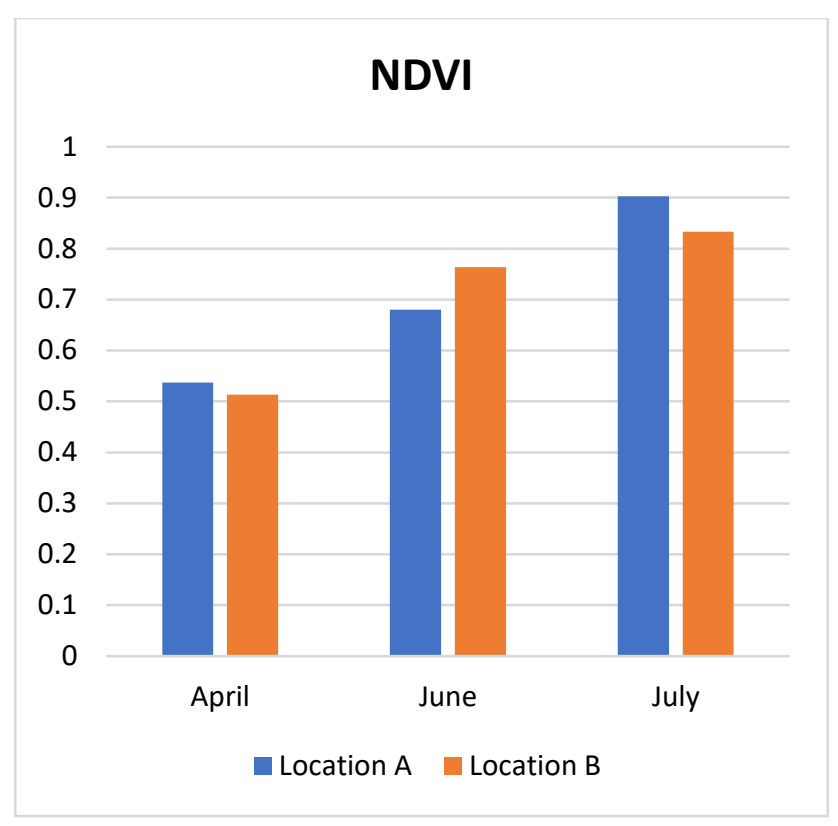

Figure 6. NDVI across two different locations in the orchard for three different months. The orchard becomes greener as the growing season progresses.
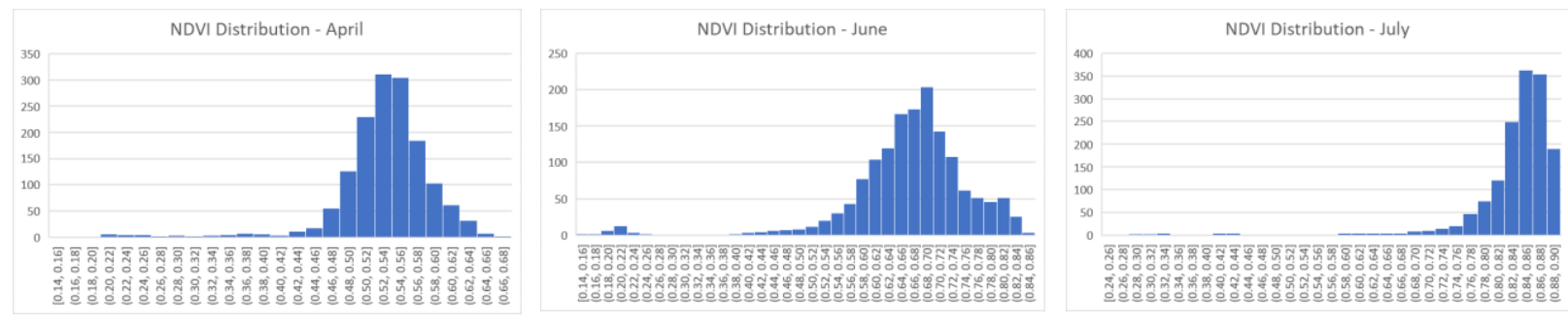

Figure 7. NDVI distribution across three different months. With time, the NDVI distribution moves right. Mean NDVI values were April: 0.53, June: 0.66, and July: 0.83

The imagery data also helps with the placement of the sensors that can further help in analyzing the IoT sensor data in the field.

\section{IoT Sensor data}

There are multiple sensors deployed in the Grandview orchard measuring different aspects of the environment and plant growth. I focused my research work on the following variables:

1. Soil Moisture

2. Soil Temperature

3. Soil Water Potential

4. Fruit and Stem Growth

5. Leaf Temperature

6. Sap Flow 
Each of these variables provides a window into the environmental factors around the plants, their needs, and the overall vigor of the orchard. The data provides early warning signals of irrigation needs. Given that we can isolate the sensor data based on section or sections of the orchard, we can provide specific irrigation treatment to the plants in that segment. There are three types of irrigation that farmers typically deploy in orchards: overhead sprinklers to cool the canopy and keep the leaf temperature stable, drip irrigation that keeps the soil moist, and under-tree sprinklers that maintains a healthy cover crop between rows. Leaf temperature thresholds can be used to trigger the overhead irrigation and drip irrigation to water the root zone.

Similarly, the soil moisture sensors can detect if the soil is getting drier in specific segments and is in need for an irrigation event. An important analysis is done by the data from SoilOptix sensors which measures soil texture. For example, sand in the soil will hold water for a shorter time while clay/slit will do so for longer periods of time. The SoilOptix sensor can help identify such zones and inform the irrigation system to change irrigation frequency and/or irrigation system design accordingly. Traditional irrigation methods will just trigger irrigation for the whole orchard even though not every section needs water. In the case of heatwave events, the whole orchard might need water, but certain sections will dry out more, requiring additional irrigation. The soil moisture sensors are generally placed at four different depths to ascertain how the temperature and moisture levels are shaping up. Each of these data feeds can be utilized to set a threshold for triggering irrigation. The percolation rate (rate of water movement through the soil) also informs the grower on irrigation strategies, for example, faster movement/travel through the soil means that grower should consider shorter durations but higher frequency of watering, use double drip lines, or larger nozzle sizes to distribute more water to such locations.

Fruit growth is a measurement to ensure that fruits are growing, on average, as expected. During extreme heat wave events, the growth can shut down until the ideal temperature is restored. If the growth is paused for a long time, the fruit starts to lose its color and cells start to break yielding undesirable apples. Figures 8-13 provide a snapshot of the data feeds from various sensors in the Grandview orchard over the course of summer 2021. The trends can be used to understand the trigger points, the correlation to heat waves, and potential solutions based on these inputs that can inform the irrigation strategy for the farm. 


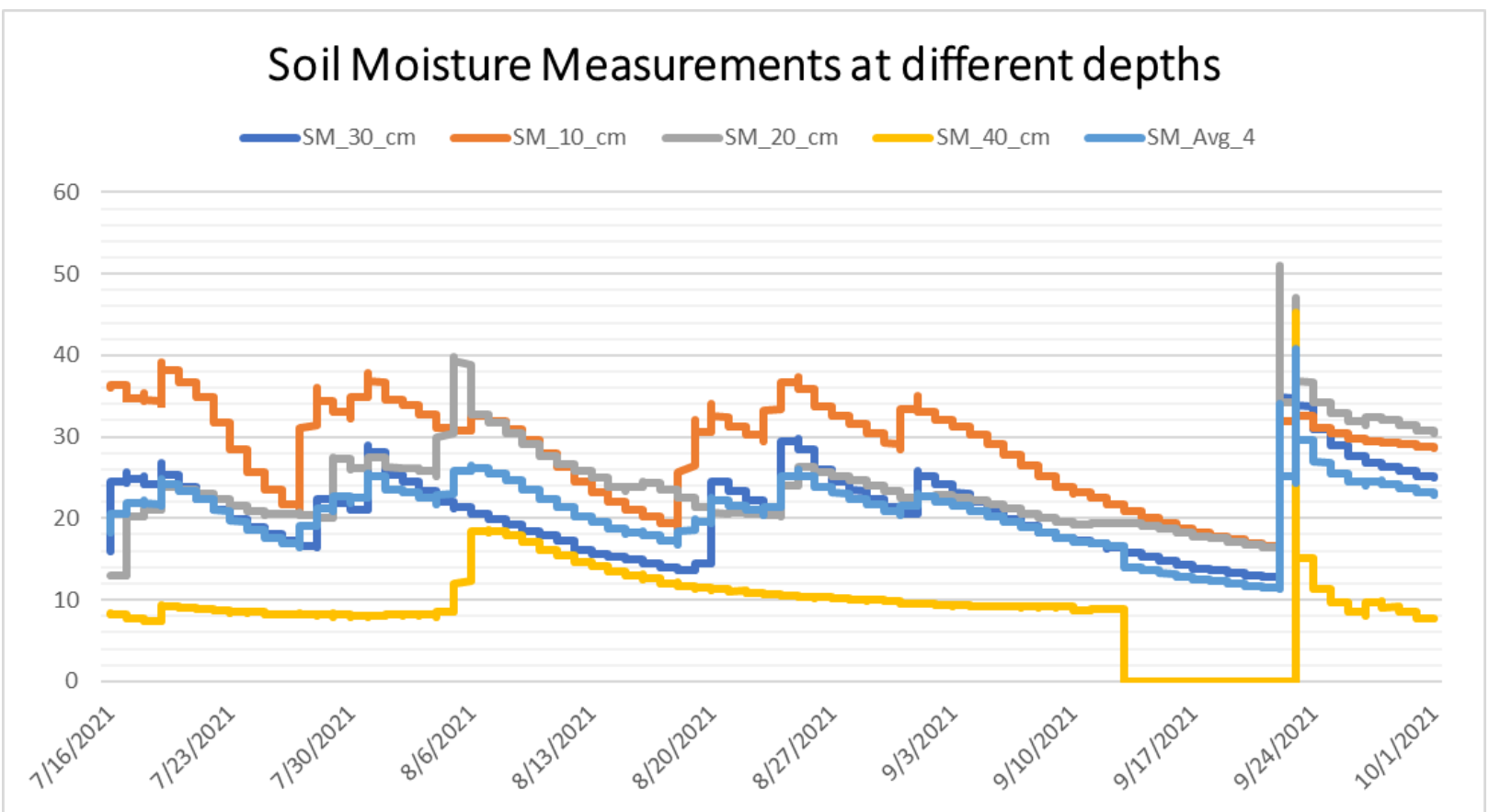

Figure 8. Soil moisture measurements at different depths. The declining lines indicate that the soil is drying out and the vertical change in the trend indicates an irrigation event.

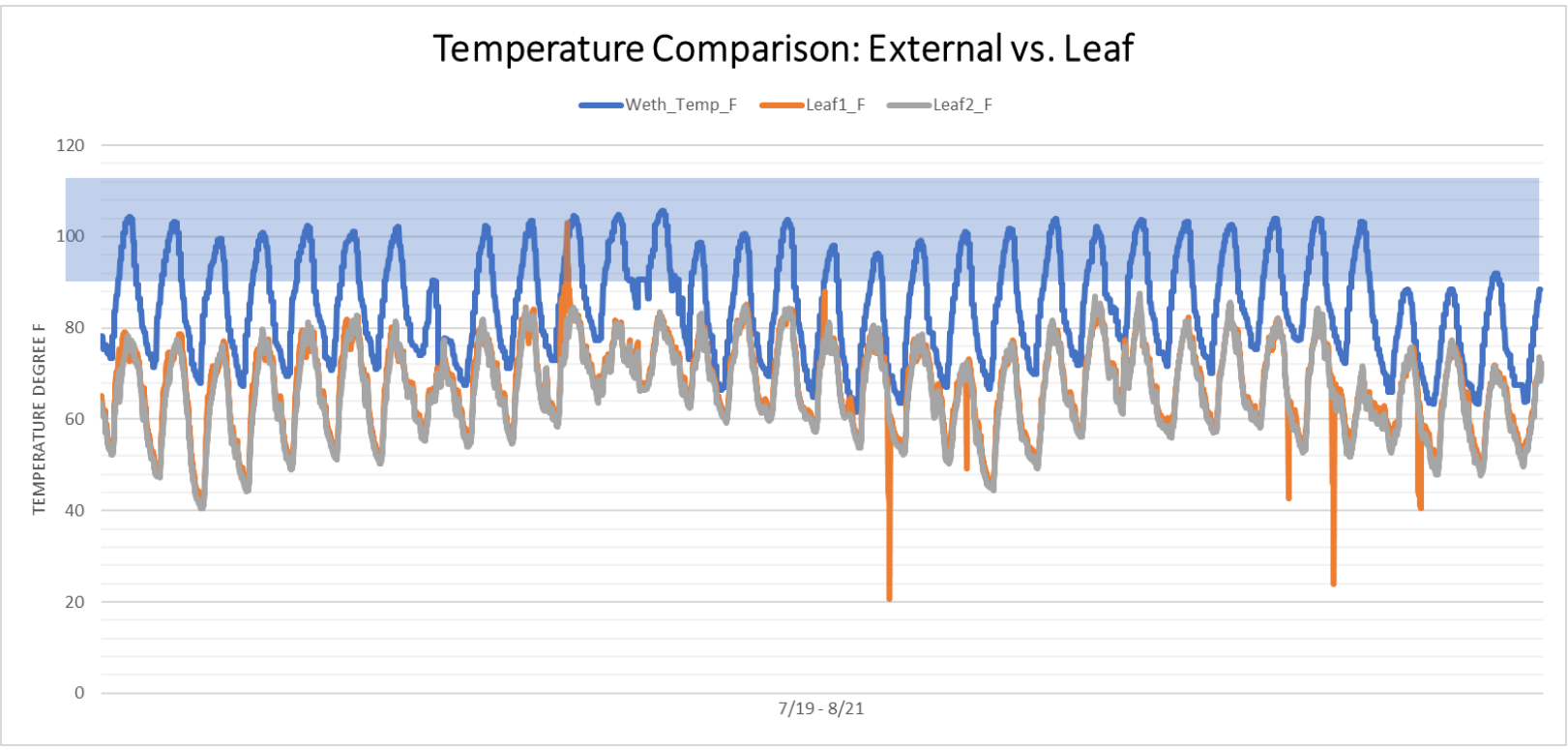

Figure 9. Temperature comparison - external (atmospheric) vs. leaf

Sap flow measures the water flow from soil to stem to get an estimate of the transpiration rates. Heat has an impact on the sap flow - as air and canopy temperature rise, the cumulative sap flow 
for the day rises as well. It resets at night when sap flow tends to go to zero. Sap flow thresholds can be set to trigger irrigation to ensure plant is not under water stress.

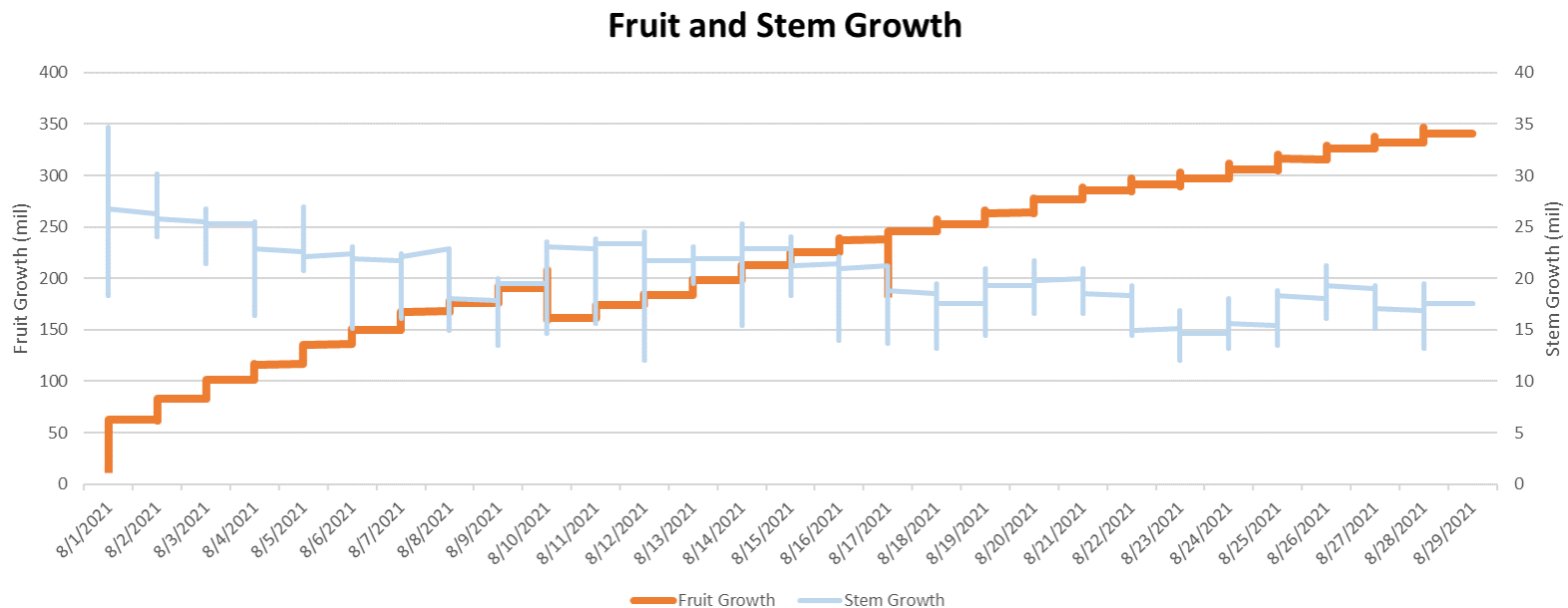

Figure 10. Fruit and stem growth through the growing season. As the season progresses, tree focuses its resources on growing the fruit while stem growth declines.

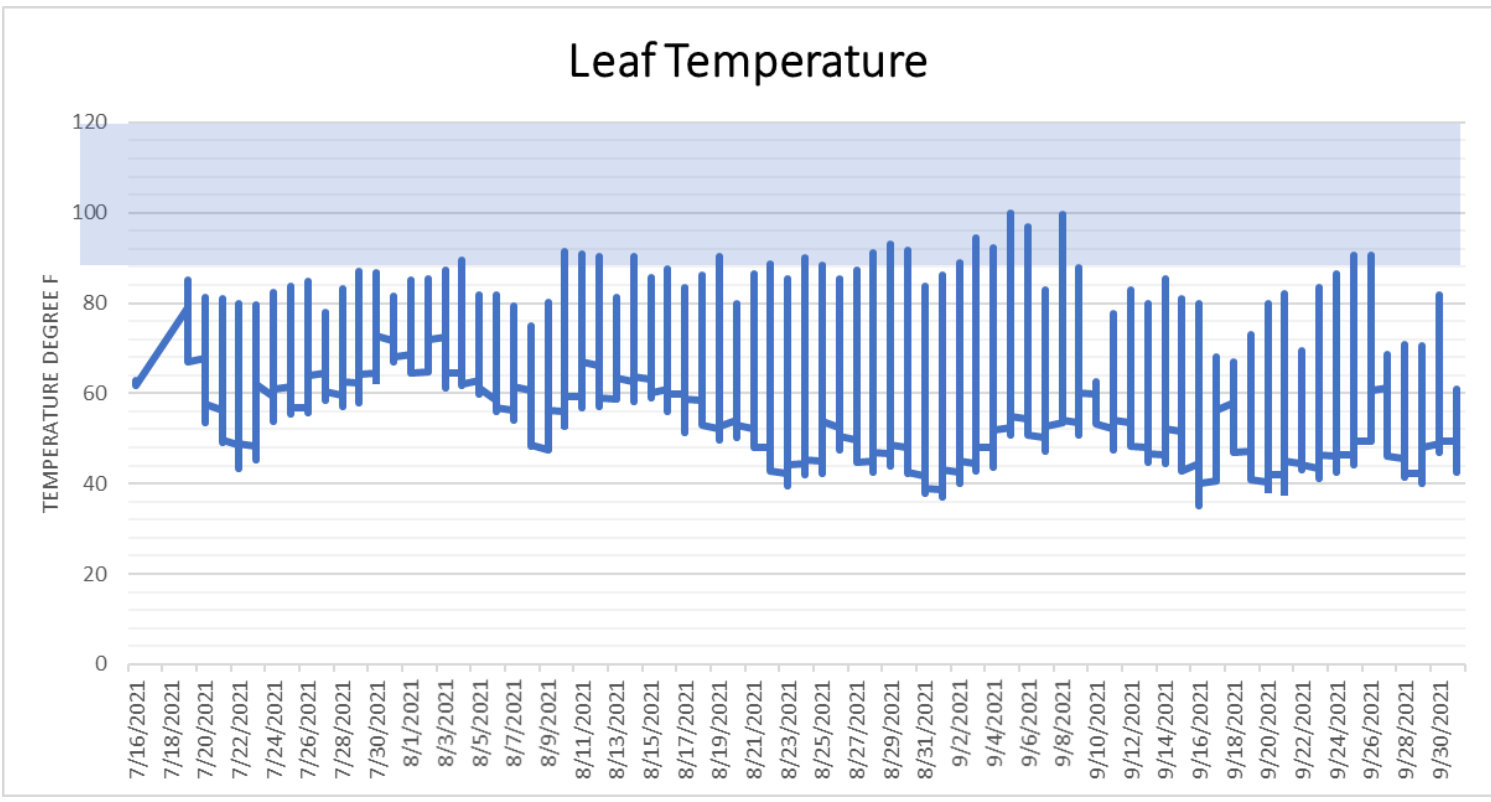

Figure 11. Leaf temperature fluctuations through the growing season

As stated earlier, NDVI provides an indication of orchard health over time. If we study how NDVI changes in the Grandview orchard, we can find some insights that can inform the farmers about the overall health as well as stress segments of the orchard. I looked at the drone imagery data collected in April, June, and July, more specifically the NDVI values of each of the segments in the orchard. If we look at how values changed from April to June and from June to July, $67 \%$ of the 
orchard grew greener during the latter months but 33\% of the segments didn't display the same characteristics (Figure 14).

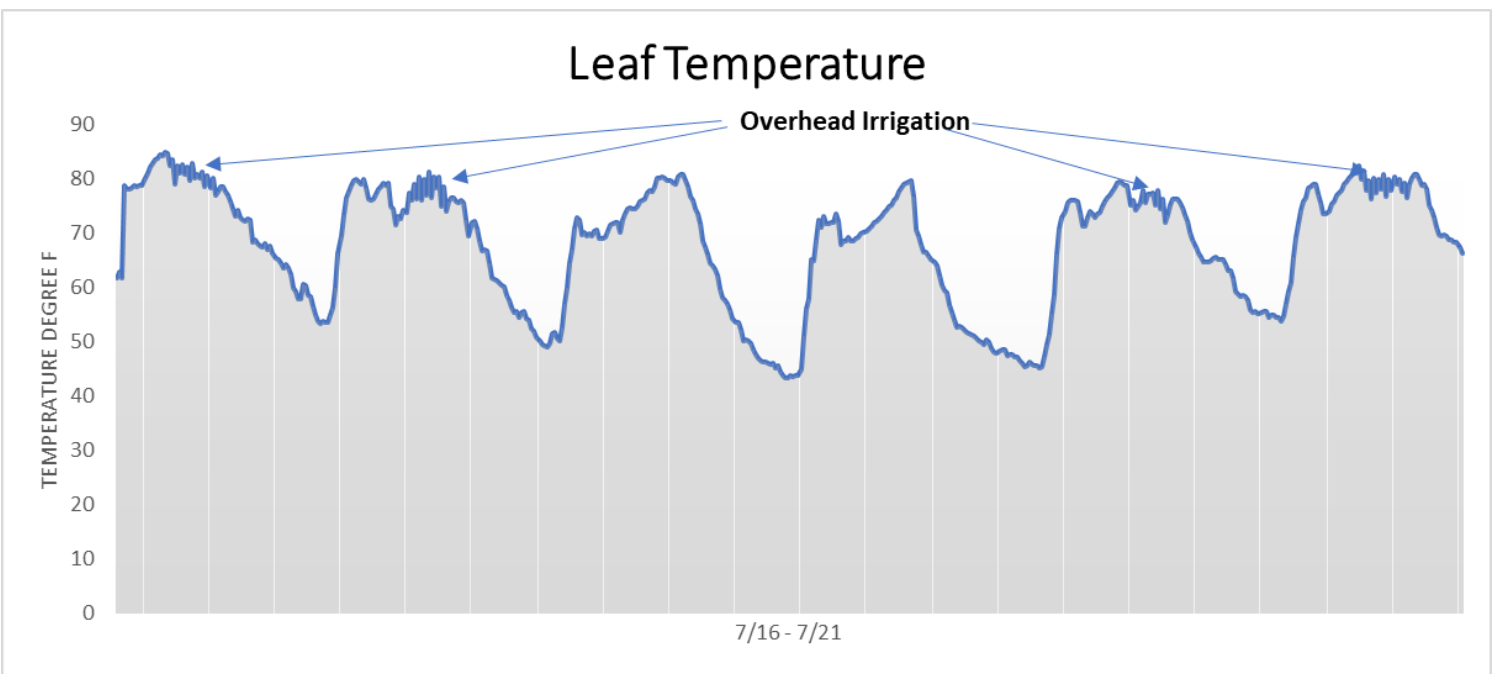

Figure 12. Leaf temperature readings showing the effect of overhead irrigation which cools down the plant

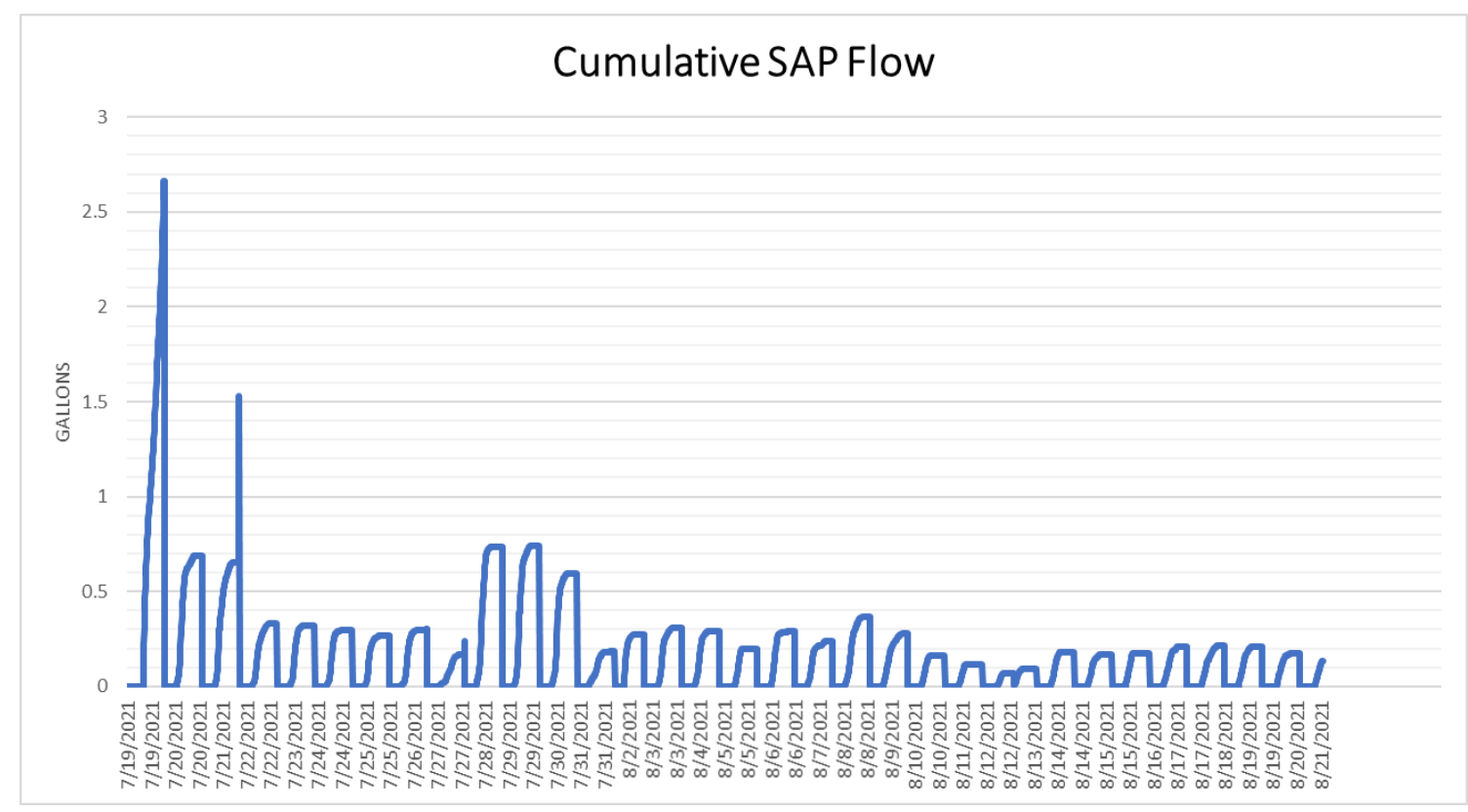

Figure 13. Cumulative SAP Flow

On further inspection, this was primarily due to less density in the canopy of the plants in those segments as well as potential heat stress that could be mitigated with more proactive irrigation and soil treatment. To develop such an irrigation strategy, one must rely on the sensors on the ground and on the plant which provide constant pulse of the orchard. 


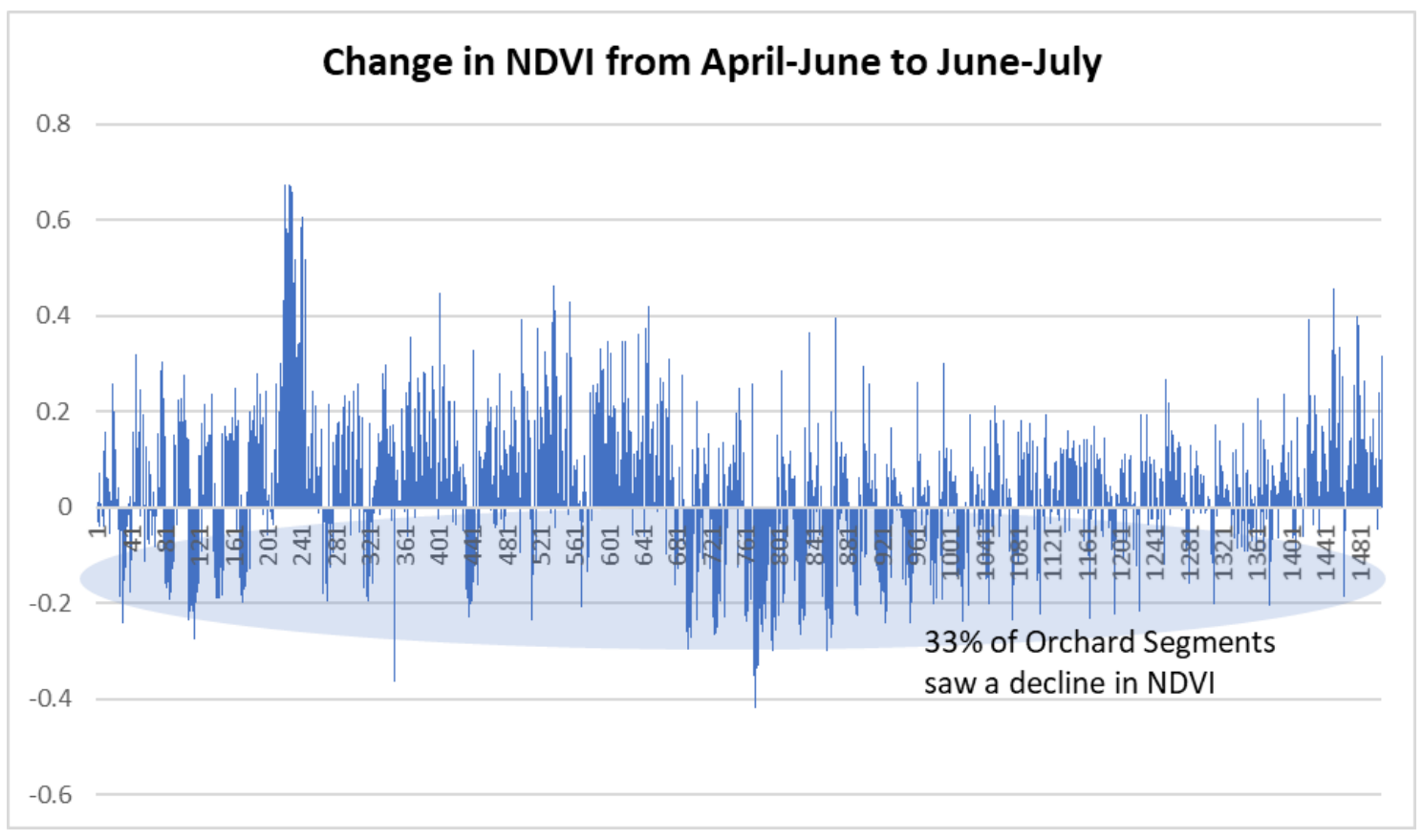

Figure 14. Change in NDVI for different orchard segments from April-June to June-July

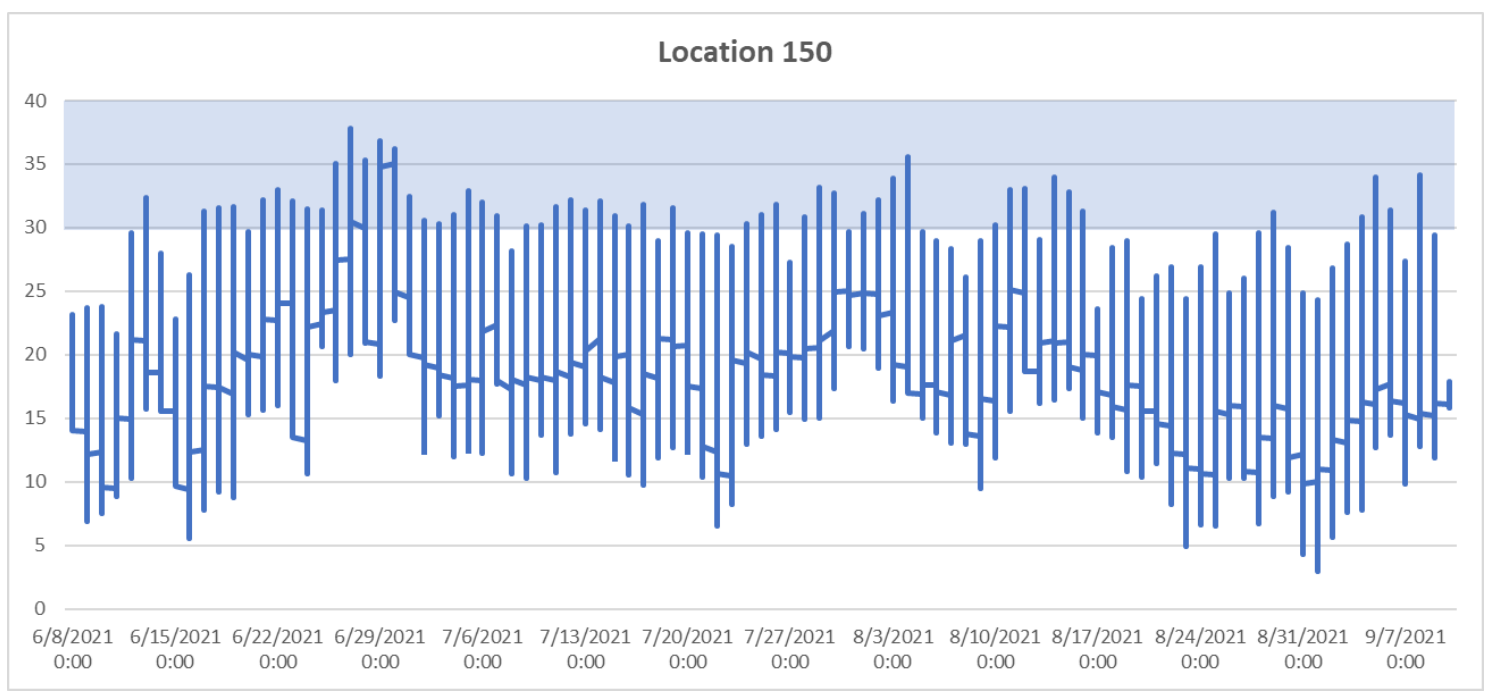

Figure 15a. Canopy temperature of sensor location 150 (0:00 refers to the midnight hour as the starting point for each day)

Figures $15 \mathrm{a}-\mathrm{b}$ provide temperature data from two different locations in the orchard. Location 150 is on the outskirts of the orchard while location 154 is deep inside the orchard. The plants inside the orchard tend to stay cooler than the plants on the periphery or the outer layer of the orchard. As can be seen in the charts, there were more heat stress days in location 150 compared to 154 for the 
same time period. Thus, the irrigation treatment for 150 has to be different than 154 triggered by what plants are experiencing. Also, one doesn't need to water the entire orchard if only a few segments need attention. This micro-climate-based approach can minimize crop damage, maximize water usage, and lower costs.

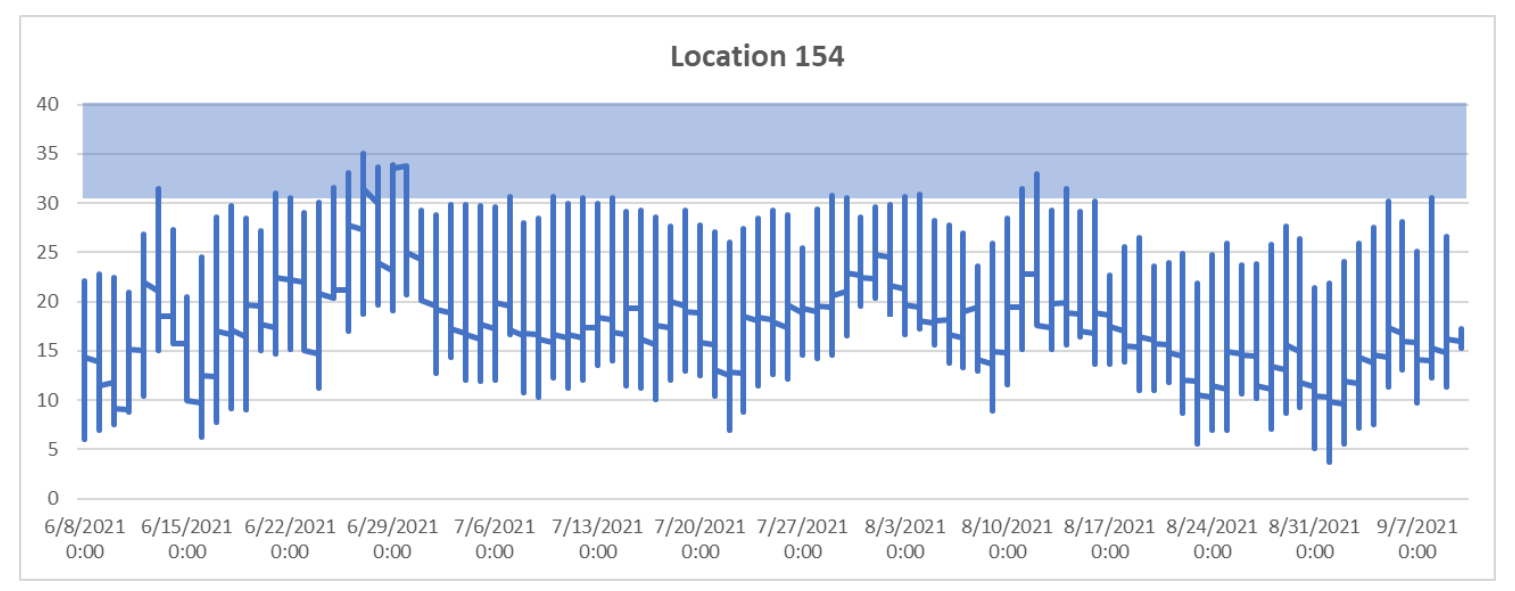

Figure 15b. Canopy temperature of sensor location 154

This framework for decision making that is optimized for resources can be applied universally across crop types or geographies. The basic idea is to use the sensors to provide feedback throughout the growing season so that the tasks such as irrigation, pruning, harvesting, supplementing nutrients etc. can be optimized based on the data from specific zones in the fields vs. simply applying them across the farm all the time. This will help in cost savings. A basic cost model is discussed below to illustrate the analysis that can be undertaken on a field-by-field basis. In our drone imagery analysis, I observed that as the season progressed, the fields grew greener as indicated by the NDVI values however, for $33 \%$ or 509 segments of the orchard, the NDVI value didn't appreciate from June to July as they did from April to June.

This can allow farmers to concentrate on these specific segments or areas where bulk of these segments reside to formulate an irrigation plan. Higher NDVI value correlates to denser vegetation which generally yields higher crop.

Further, if we analyze the soil temperature data (that is collected every 10-15 minutes) across two locations, one in the middle of the orchard while the other is close to the periphery, we can clearly see the difference. Site 150 is generally hotter relative to site 154 (please refer figure 5 for reference) and as such requires more irrigation. Irrigation systems can be programmed to automatically turn on when the soil temperatures (max temperature sustained for at least 30 minutes) consistently breach a set threshold (such as $90^{\circ} \mathrm{F}$ ) during the day, but the watering is 
limited to those segments vs. the entire orchard. Too much irrigation can harm the crop as well by washing away the key nutrients.

The soil water potential (measured in $\mathrm{kPa}$ ) is especially useful in assessing the state of the soil at given moment to determine the irrigation needs (Figure 16). ${ }^{14}$ Typically, for optimal growth the soil water potential should be in the range of -10 to $-15 \mathrm{kPa}$ (this will vary with crop and region).

If the values are greater than $-10 \mathrm{kPa}$, it indicates that the soil is saturated, and more irrigation might actually harm the soil. On the other hand, if the values are lower than $-15 \mathrm{kPa}$, it indicates that soil is getting drier and needs attention. Sometimes, faulty driplines can be detected looking at these readings.

A key aspect of the Grandview laboratory is how the data is collected and processed. While the US is seeing a deployment of $5 \mathrm{G}$ across the country, availability of any meaningful cellular coverage is absent in rural farms. Further, the signal degrades rapidly as one goes deeper into the orchard. So, a mesh-based system must be installed that can relay the data to a central repository in real-time. Additionally, the size of some datasets is so large that it is cost prohibitive to transmit such data to the cloud in real-time. IoT sensor data is generally only a few kilobytes whereas drone and ATV imagery data is in gigabytes and terabytes.

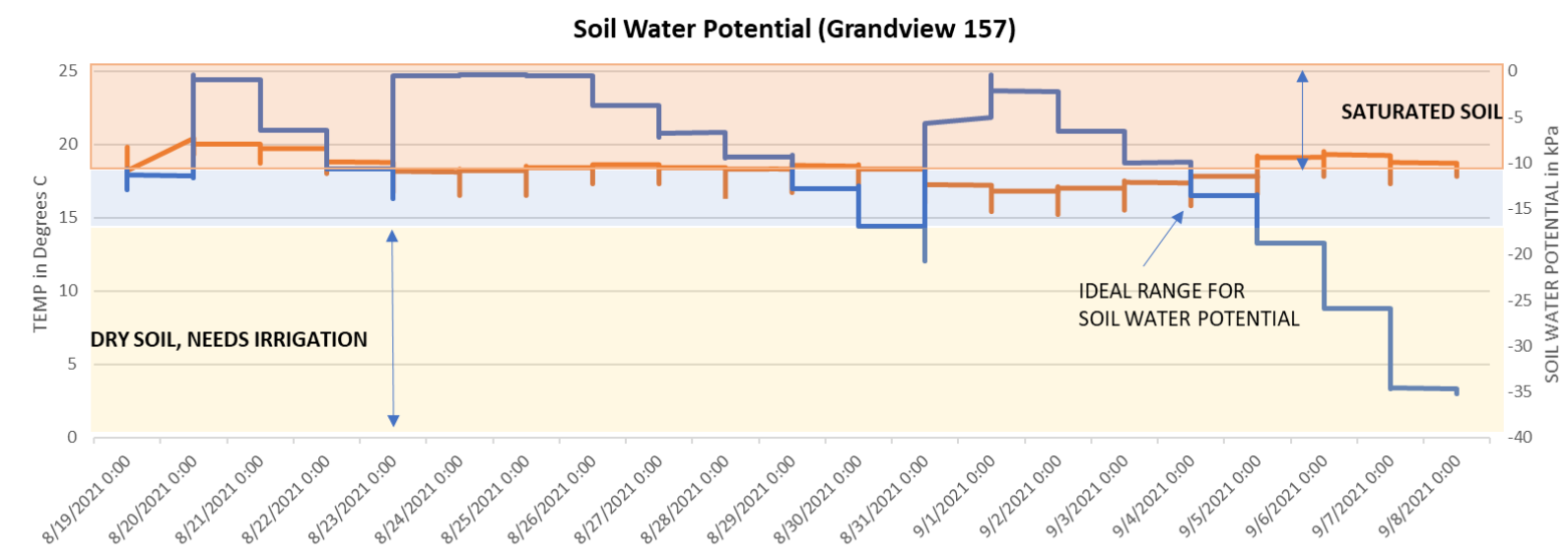

\section{Figure 16. Soil water potential for sensor location 157}

A mobile edge data center was used by innov8.ag to process the data at the farm and extract the necessary insights that can be uploaded to the cloud when optimal conditions become available. Such a technology architecture is necessary to simplify operations and ensure that technology doesn't become the problem. As more drone and LiDAR data is used on the farms, edge computing 
becomes central to the operations so that data can be analyzed quickly, and insights related to the farmers in a timely fashion.

\section{Decision Framework and Implications}

The decision framework (Figure 17) is designed on a threshold-based algorithm that can be adapted to any crop or field.

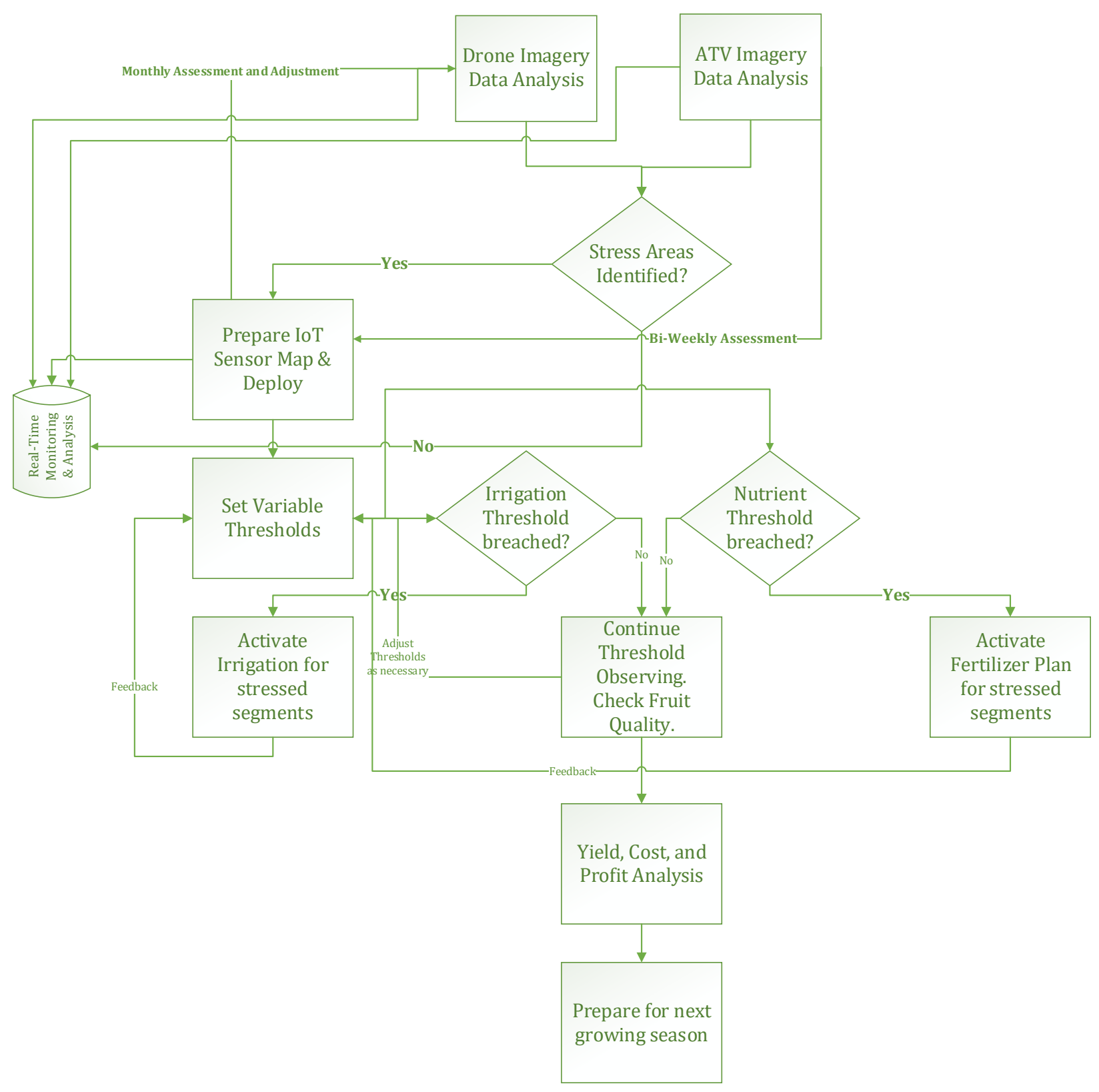

Figure 17. Threshold-based decision framework 
Different farmers will have varying needs and data feeds depending on the crop, weather conditions, historical patterns, and the resources available, However, the basic principles are the same - use drone imagery to get an overall assessment of the field and growth trends and then use IoT sensor data for more specific assessment of soil, plant, and crop conditions during the growing season.

Once the sensors are in place, apply the thresholds for various measurements such as atmosphere, canopy, and leaf temperatures, soil moisture, soil water potential, sap flow, NDVI, plant, stem, and crop growth. Thresholds that trigger irrigation can be set either for each one of these variables or in combination. The threshold can vary by the month of the growing season or specific weather patterns, for example, if a heat wave is expected, one might want to preempt the excessive heat conditions with overhead and drip irrigation and increase the frequency of overhead irrigation to keep the plants cooler.

These algorithms can be further optimized for resources, automation, and specific conditions that the farmer might be dealing with. For example, excessive heat might activate some of the labor laws that don't allow workers to work continuously in high temperature conditions. In most places, the employers are required to provide shade when temperatures rise above $80^{\circ} \mathrm{F}$ and 15 -minute breaks in the shade each hour when temperatures rise higher.15 This impacts resource availability on certain days especially when they are needed the most. In such cases, automation can optimize for both weather conditions as well as resource availability to tweak their irrigation thresholds. Enough historical data will provide guidance with the help of predictive tools that can anticipate such demands based on weather forecasts.

It is also critically important to measure fruit quality throughout the process to ensure that that fruit quality is not being adversely affected by the abiotic stress. ${ }^{16}$

Irrigation based on triggers affords the capability to address irrigation based on need and science versus whole irrigation of the entire acreage which not only wastes precious resources but can also damage the soil. The basic algorithm to design a threshold-based system is highlighted in figure 17. It can be combined with economic and pricing data to produce a full cost and profit analysis for the farm.

\section{Potential Cost Savings}

We can formulate some opinions about the range and directionality of potential cost savings. I created a model to estimate cost savings from a IoT sensor-based system discussed in this paper. 
First, I looked at the NDVI values of each segment for a given month and if it is lower than the average for the entire field, then it passes the initial threshold for irrigation. Other segments with higher values don't require as much irrigation. There are two types of irrigation strategies considered - dripline and overhead. For dripline, the soil water potential is used as a threshold (-10 to $-15 \mathrm{kPa}$ ) and for overhead irrigation, leaf temperature ( $>80$ degrees $\mathrm{F}$ ) is used. If any of these values are breached, we will turn on the respective irrigation system otherwise we won't. This will only activate irrigation if it is needed in the segments that need it the most. Based on this algorithm applied to the Grandview apple orchard, I estimated that roughly 55\% of the water related costs could be saved over the growing season (April-September).

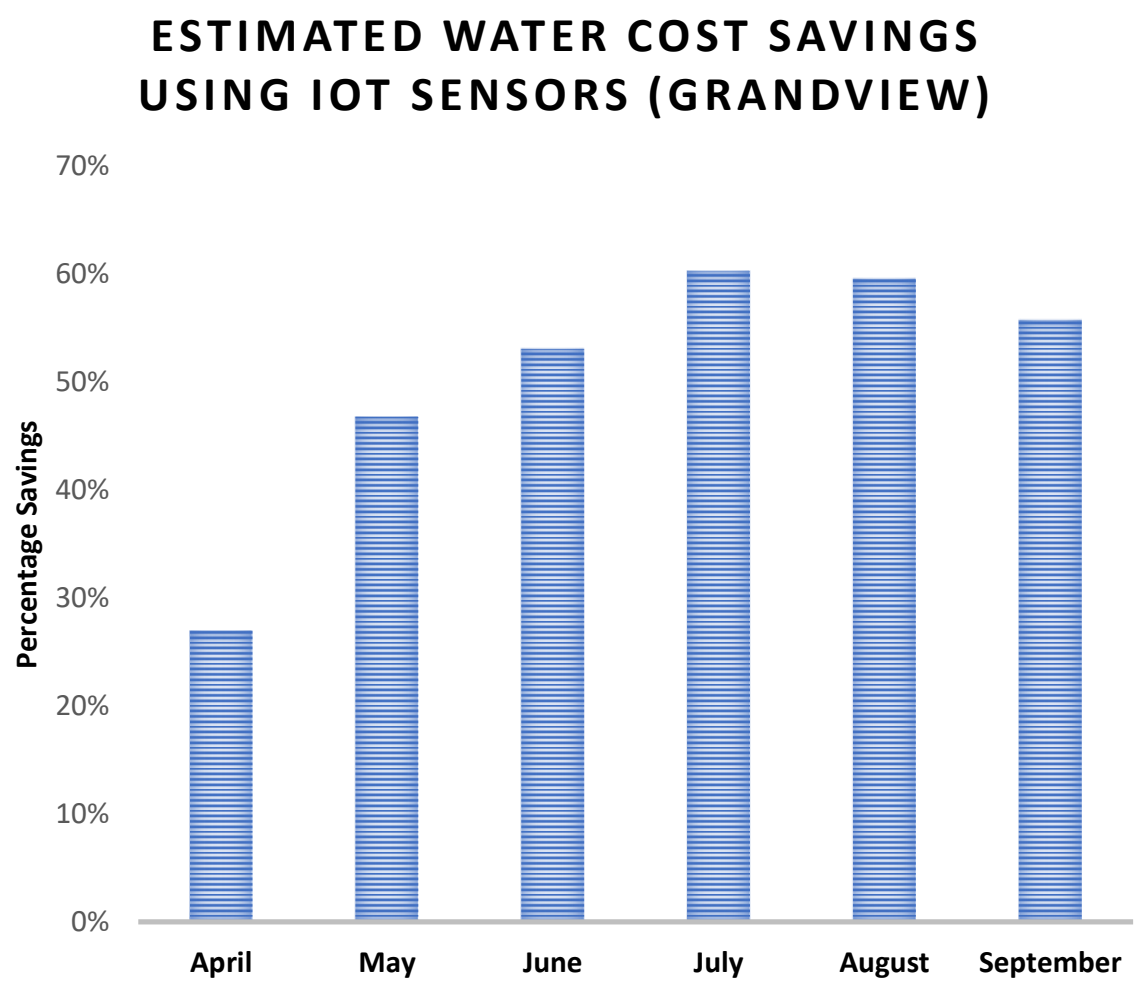

Figure 18. Estimated water cost savings using IoT-sensor-based decision system

Depending on the cost of water, this could amount to substantial savings which can contribute towards profits or be used for further investments. In 2018, US farms irrigated 55.9 million acres with 83.4 million acre-feet of water and sprinkler system was the most widely used distribution method according to the USDA. ${ }^{17}$

Further, according to the USDA, in 2018, the irrigation expense for the US was $\$ 6.6$ billion with the average per farm expense being $\$ 82,300$ per year. Five states - California, Nebraska, Arkansas, 
Texas, and Idaho account for $50 \%$ of US irrigated acres. Washington with 4.1 million acres was seventh on the list. The cost of water especially during stress months can vary significantly by state and location. Water is scarcer in southern Oregon and in California compared to Washington state so the local resource economics will dictate the design of a sustainable strategy.

Clearly, all farms can't be automated in the short-term. This process will take time, but one can focus on the most vulnerable farms in the country based on climate patterns and weather forecasts. As indicated in figure 2, the crop losses from heat and drought are multiplying every decade and we need to find solutions to mitigate the risks and high costs that will inevitably spiral out of control if left unaddressed. The sensor-based system will also help mitigate farmer's weather pricing spikes that result from drought conditions and better manage dwindling resources. Grower might have to develop both short-term strategies and long-term plans. For example, zone-based irrigation requires the retooling of the irrigation system (which includes pipes, pumps, valves, controls, sensors, emitters, etc.) which might be difficult to do in the middle of a growing season. However, one can alter the frequency and duration of the existing irrigation sets and add additional drip lines in areas of need to compensate for a complete overhaul of the irrigation system for the specific farm.

\section{Recommendations and Future Work}

The sensor and network technologies have improved over the course of the last decade to a point that the relatively inexpensive sensors can be placed in farms to provide near real-time feed into a cloud and edge data repository for analysis and actionable insights. As the results from this project show, the data can be used not only to automate irrigation and planning of resources but also to manage water availability throughout the season. It not only accelerates the treatment of stressed plants and segments of the farm but also optimizes the costs of irrigation, power, and labor. Growers can follow a two-step process for automation: first use the imaging data to consider sensor placement for real-time insights and then use the sensors to automate irrigation coordinated with the human resources on the field. A shift towards automation will also require worker behavioral adjustments. Over time, the irrigation crew will need to adjust their schedules as the farm moves from being lightly automated to highly automated with remote monitoring. Future work can study these patterns across different types of crops in different geographic locations to see how the threshold algorithms can be adjusted and benchmark the environmental, growth, and thresholds by crop and region to provide more control to the farmers. 
While scientists thrive in large datasets, we need tools for the farmers to easily process the data in a visual format and make sense of the insights data. One of the promising techniques to visualize data is through Augmented Reality (AR) and Virtual Reality (VR). AR data layers can overlay the actual farm to give a richer picture of what's happening on the ground while the crew is onsite. VR can relay the information to a lay person in a matter of seconds what a 20-page report can't. A direct feed from the centralized and edge cloud network can enable VR experience for the farmers that can be quite beneficial.

The data can be further tied to the output data of yield and insurance costs to understand if such a system can help maximize profits across a wider range of crops. Climate change is a reality, and we are likely to see an increasing number of severe heat episodes each year. The supply of water is not increasing even though its demand continues to escalate. This has a direct impact on costs associated with irrigation. Technology can assist farmers in managing the risks and better prepare for the future. Grandview farm laboratory provides a window into the future of how farms can and should be managed using sensors that provide deeper and actionable insights to farmers, researchers, and policy makers to keep the food supply secure and farm communities sustainable. 


\section{Bibliography}

${ }^{1}$ AR6 Climate Change 2021: The Physical Science Basis, https://www.ipcc.ch/report/ar6/wg1/

${ }^{2}$ Headline Statements from the Summary for Policymakers, Aug, 2021, https://www.ipcc.ch/report/ar6/wg1/downloads/report/IPCC AR6 WGI Headline Statements.pdf

${ }^{3}$ Global Climate Report - Annual 2020, https://www.ncdc.noaa.gov/sotc/global/202013

${ }^{4}$ Hidden Toll of the Northwest Heat Wave: Hundreds of Extra Deaths, Aug, 2021, https://www.nytimes.com/interactive/2021/08/11/climate/deaths-pacific-northwest-heat-wave.html

5 Troubled Waters, Blackrock Investment Institute, July, 2020, https://www.blackrock.com/us/individual/insights/blackrock-investment-institute/troubled-waters ${ }^{6}$ Extreme heat effects on perennial crops and strategies for sustaining future production, Parker et. al, Plant Science, 2020, https://www.climatehubs.usda.gov/sites/default/files/ParkerEtal2020 PlantScience.pdf

${ }^{7}$ Consistent negative response of US crops to high temperatures in observations and crop models, Schauberger et al., Nature Communications, 2016, https://www.nature.com/articles/ncomms13931 8 World Water Development Report, United Nations, March 2018, https://www.unwater.org/publications/world-water-development-report-2018/

${ }^{9}$ Data collected from AgRisk Viewer - https://swclimatehub.info/rma/rma-data-viewer.html, 2019, Losses are estimates to complete the decade analysis. The data is discussed in detail by Julian Reyes and Emile Elias in their paper, "Spatio-temporal variation of crop loss in the United Sates from 2001 to 2016" published in 2019, https://iopscience.iop.org/article/10.1088/1748-9326/ab1ac9

10 The global value of water in agriculture, D'Odorico Paolo et al., PNAS, Sept 2020, www.pnas.org/cgi/doi/10.1073/pnas.2005835117

112021 Smart Orchard Launch at Washington Fruit \& Produce with Researchers, Tech Providers, and Growers, July, 2021, https://www.innov8.ag/post/2021-smart-orchard-launch-at-washington-fruitproduce-with-researchers-tech-providers-and-grower

12 Washington state apples expecting lighter crop volume, Sept, 2020, https://fruitgrowersnews.com/news/washington-state-apples-expecting-lighter-crop-volume/

13 Washington Fruit \& Produce Co., https://www.washfruit.com/

14 Why this sensor has made the tensiometer and gypsum block obsolete, https://edaphic.com.au/whythis-sensor-has-made-the-tensiometer-and-gypsum-block-obsolete/

15 https://abcnews.go.com/Technology/wireStory/washington-state-latest-pass-heat-rules-workers$\underline{78762718}$

16 Water Deficit Timing Affects Physiological Drought Response, Fruit Size, and Bitter pit Development for Honeycrisp Apple, Michell Reid, Lee Kalcsits, Washington State University, 2020,

https://www.mdpi.com/2223-7747/9/7/874/htm

17 Irrigation and Water Management - Results from the 2018 Irrigation and Water Management Survey, USDA, Nov, 2019, https://www.nass.usda.gov/Publications/Highlights/2019/2017Census Irrigation and WaterManagem ent.pdf One acre foot is the amount of water required to cover one acre to a depth of one foot. This is equivalent to 325,851 gallons or 43,560 cubic feet of water. 